\title{
Preliminary Design Support by Integrating a Reliability Analysis for Wind Turbine
}

\author{
Hamid Zaghar, Mohammed Sallaou, Ali Chaâba \\ Team M2I (Mécanique Ingénierie Intégré) Mechanical Engineering Integrated, \\ Department Mechanics \& Structures ENSAM, Moulay Ismail University, Mansour, Morocco \\ Email: zagharhamid@yahoo.fr
}

Received March 9, 2012; revised April 17, 2012; accepted April 28, 2012

\begin{abstract}
In the context of industrial competitiveness, taking into account the process design throughout the product life cycle is inevitable, from the expression of the need to recycle. Because of increased knowledge, the capitalization and knowledge management are increasingly targets that companies seek after. Indeed, during the approval phase, studies and scientific researches have generated knowledge that especially concerning the reliability of system components. In this context, the capitalization and reuse of knowledge are necessary and they have a particular interest in design and particularly in the preliminary design phase. Studies are already completed, and they suggest a design process that ranging from the need to the problem solving. At each phase of the process, structural characteristics are defined by the designer through the available knowledge already capitalized to make choice of component and their arrangement. This article proposes integrating the analysis of system reliability in this process. The objective is the use of knowledge in the vision safety and hazards of operating through the study of reliability and decision making for the selection of solution.
\end{abstract}

Keywords: Preliminary Design; Reliability; Wind Turbine; Gearbox

\section{Introduction}

The conventional design process based on an iterative procedure is structured in successive phases, allowing to converge to valid solutions through trial-error testing [1]. In addition, all the knowledge needed to design a product may not be all taken into account simultaneously. The preliminary design is one of the important phases of this process. This phase involves itself about $70 \%$ of the total cost generated in the project design itself [2]. Thus, the choices made during the preliminary design are fundamental and therefore their challenge is possible to be the least common [3].

The knowledge capitalization used and applied during the design process is worthy to be optimized if necessary. To make this task successful, its structure and its organization have become a priority to formalize knowledge and reuse.

This knowledge is related to various multidisciplinary views such as functional, structural and behavioral, integrating the entire product life cycle witch. It is proposed to incorporate the quality and operating safety vision through a reliability analysis. In this context, we are interested in studying reliability by the use of existing knowledge on the product itself and its components, or by the use of estimating software reliability. One of the important goals of the present research work is to bring back this knowledge to the stage of preliminary design so that they could be used as criteria for decision in the solutions choice.

This approach will be applied to a wind turbine system with a horizontal axis. Indeed, wind turbine mechanism belongs to structures whose availability ratio is weak, further, their maintenance is generally difficult and costly.

\section{Context}

\subsection{Case General}

The approach to be implemented in this work provides assistance to the designer to conduct the design process. Using capitalized knowledge related to the product under steady. For this end, we rely on a preliminary design approach based on the use of knowledge already capitalized [4] while incorporating a reliability analysis.

The approach consists, starting from the needs analysis and definition of the functional specifications, to generate and analyze the knowledge which is necessary for the success in defining and prioritizing design solutions valid. The general architecture of the approach, including the 
different stages, is illustrated by means of the flowchart in Figure 1. In the following of this section, we provide a brief explanation relating to main phases.

The definition phase of components is performed at a given level of the functional block diagram. The evolution through levels is done according to the relevance of the available knowledge and its accuracy.

The analysis phase of architectures consists in defining preliminary architectures of the product from a combination of components and selection of interactions between them.

The choice of a component and hence the induced and produced effects associated with this choice permit to generate physical models related to the behavior of the component.

The consideration of some effects induced can lead to the integration of other components limiting their impact on the system.

In the context of a given problem, the designer will be able to distinguish among these variables which are the criteria $(C r)$, the design variables $\left(V_{C O}\right)$ and the auxiliary variables $\left(V_{A}\right)$. The criteria can be design variables $\left(V_{C O}\right)$ or formulated with respect to $\left(V_{C O}\right)$.

Generation of solutions requires a resolution of the global model of the system by a confrontation with the qualification criteria of the functions of Functional Specification these criteria are performance, cost, and reliability.

The resolution of these models consists of prioritizing solutions and helping the designer to make its decision. In order to make clear, this proposed approach a case study on wind turbine will be the suggest of the following subsection.

\subsection{Availability of Components Wind Turbine}

The availability of wind turbines is a very important factor for their profitability, so a better knowledge of the failure rate of each component appears inevitable. Usually, wind turbines are designed to operate for a period of 20 years. However, no final statement can yet be made concerning the real lifetime of modern large wind turbines, because so far they are in their early age.

The study of the reliability of modern wind turbines field shows a reduction in failure rate gearbox compared to other components [5]. However, it has a limited availability because of its frequent stops (Figure 2), therefore, high costs have to be engaged for repairing.

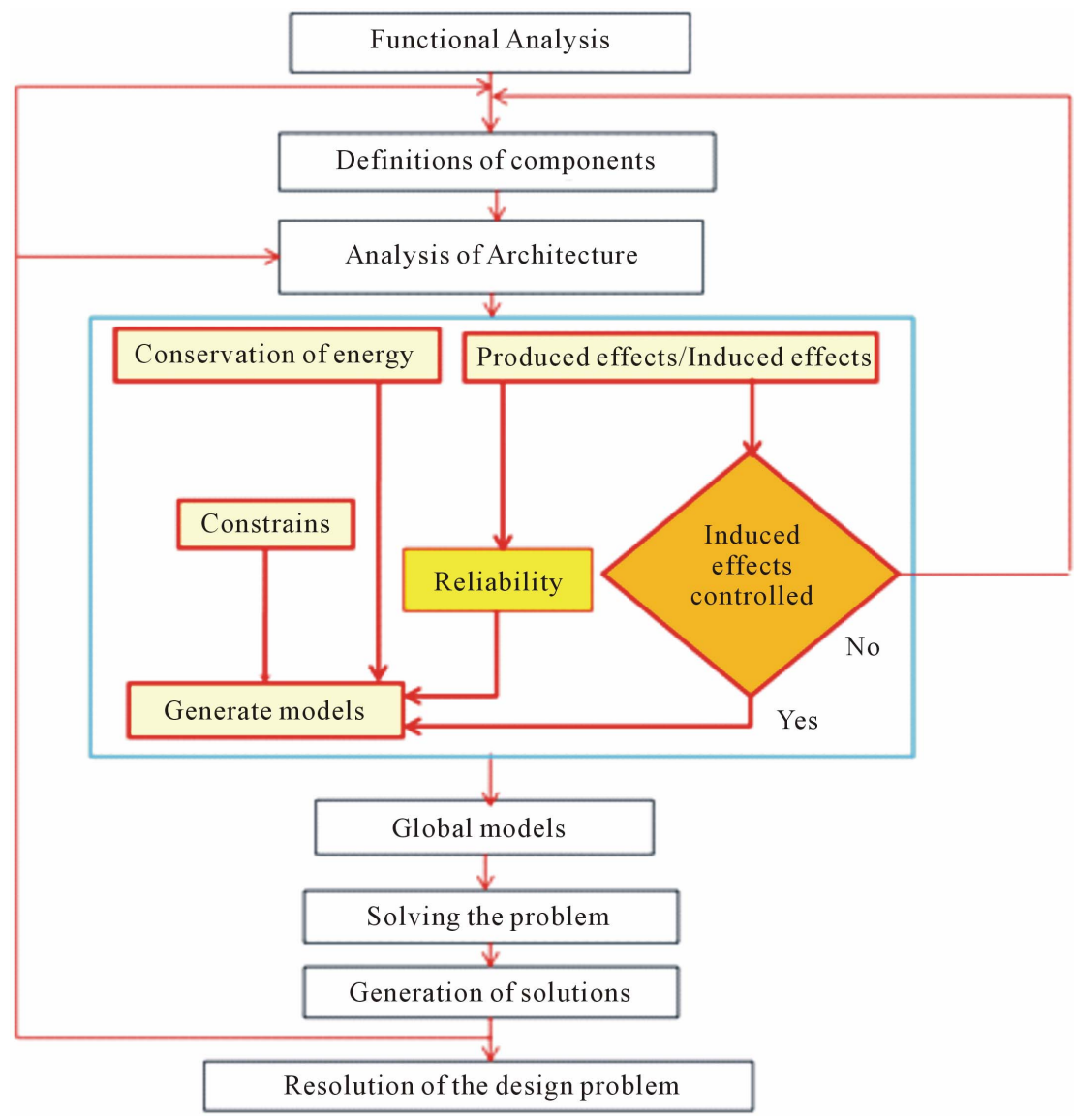

Figure 1. Preliminary design approach incorporating reliability. 

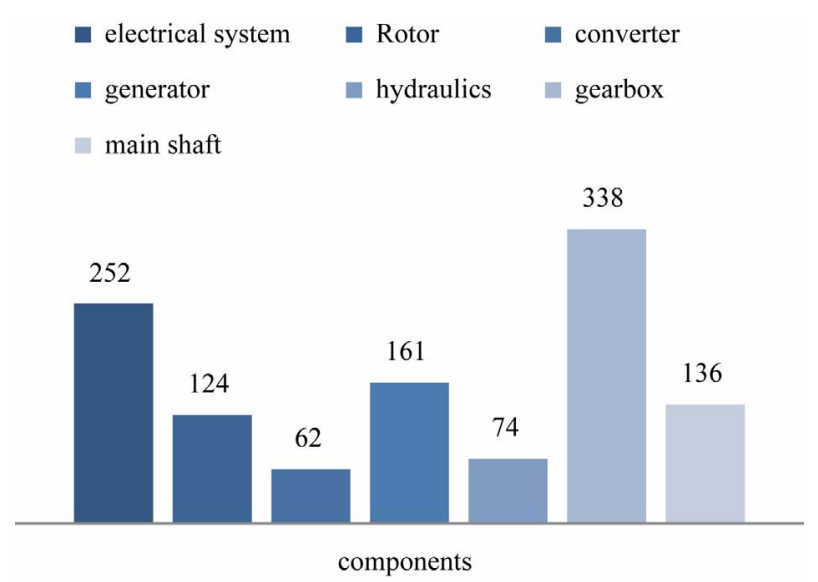

Figure 2. Downtime of the main components [5].

\section{Definition of Components}

In the phase of analysis and structuring, a design problem of a wind turbine system arise, the structural decomposition through the structural block diagram extended to external environments to describe the constitutive functional blocks of the system, particularly the gearbox [6]. Figure 3 shows a decomposition of a geared drive wind turbine.

The accuracy of such a reliability study depends on the depth and level of decomposition, for example, a wind turbine is a complex system, the study of its reliability depends on the mastery of the failure rates of its components during time. So this phase represents the first step in a reliability study.

To develop a better understanding of the performance of the reliability of different models, we consider two configurations R80 and R100. Their characteristics used by RELIAWIND, are detailed in the Table 1.

For the design of the R100 configuration, two cases are considered, either with a synchronous generator (R100-S) or asynchronous (R100-A). This results in three types of configurations, GB-R80, R100-S-GB and GB-A-R100.

The case of GB-R80 is a combination of a planetary gear train followed by two parallel stages with a transmission ratio of about 100 (Figure 4).

GB-R100-S is a combination of a planetary train spur gears followed by a planetary train helical gears, with a ratio of about 35 (Figure 5).

GB-R100-A is a combination of two planetary trains followed by a parallel stage, with a transmission ratio of about 126 (Figure 6).

\section{Energy Vision}

The logical organization can be useful to limit confusion or differences of description. The law of completeness of the parties, as defined by the TRIZ method, to distinguish for a given system, four main elements are essential to achieve the required functions in (Figure 7), this law states that the realization of a function comes from the transformation of energy (converter $\mathrm{C}$ ), this energy is then transmitted (transmitter $\mathrm{T}$ ), an operator then performs the action (operator $\mathrm{O}$ ) [8]. The law of completeness of the parties believes that a system is more sophisticated (optimal) if it contains a control function provided by a controller component. The control can be one, two, or all of the components [9].

The components must be positioned relative to a reference, which may be external to the system to a global reference level 0 or internal to the system to a local reference to a given level.

The realization of all functions of the wind turbine passes mainly by the transit of three functional types of flows, aero dynamical, mechanical, and electrical.

In this section we are interested in the decomposition

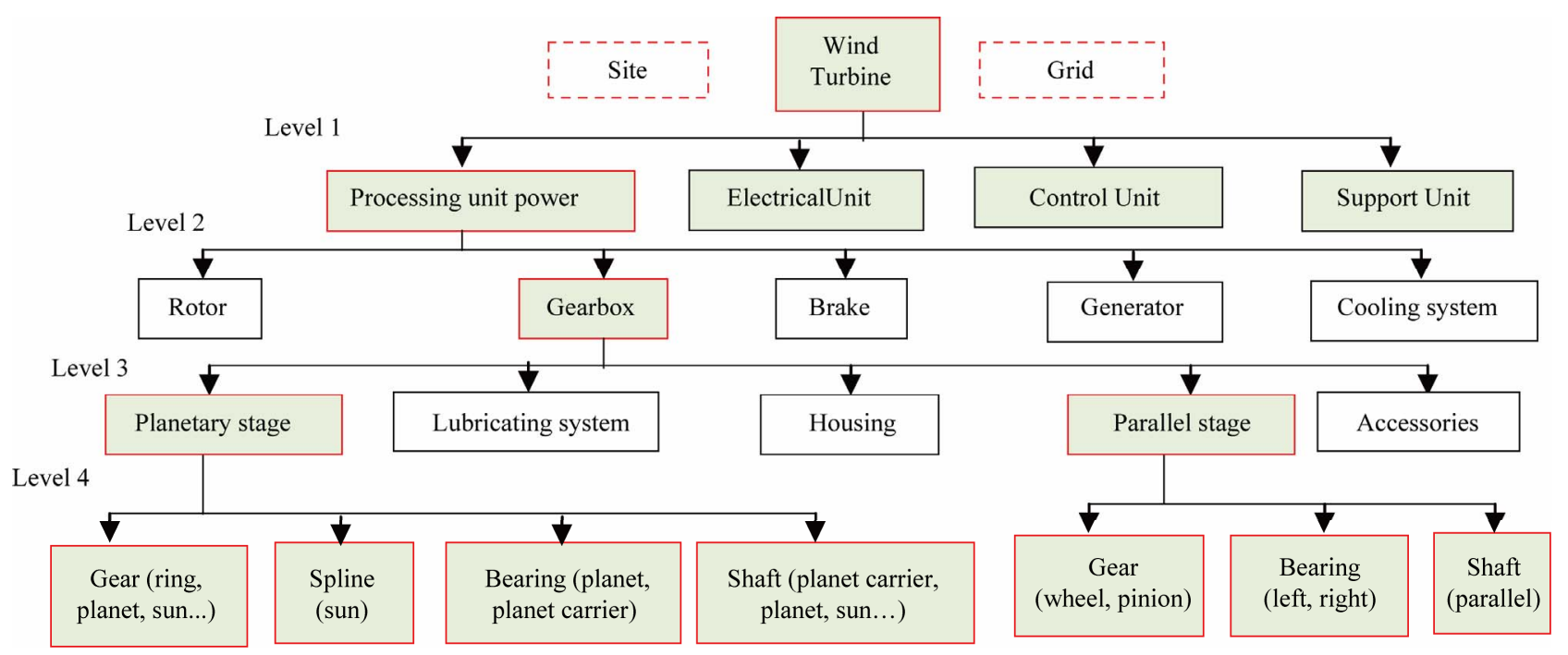

Figure 3. Structural block diagram extended to a wind turbine-level 4. 
Table 1. Characteristics of the two configurations [7].

\begin{tabular}{ccc}
\hline Characteristics & $\mathrm{R} 80$ & $\mathrm{R} 100$ \\
\hline Rated Power (MW) & $1.5-2.0$ & $3.0-5.0$ \\
Rotor diameter (m) & $80-90$ & $120-130$ \\
Height of tower (m) & $60-100$ & $100-120$ \\
Frequency of rotation (tr/mn) & $10-20$ & $14-15$ \\
Operating temperature & $-25^{\circ} \mathrm{C}-40^{\circ} \mathrm{C}$ & $-25^{\circ} \mathrm{C}-40^{\circ} \mathrm{C}$ \\
Number of blade & 3 & 3 \\
\hline
\end{tabular}

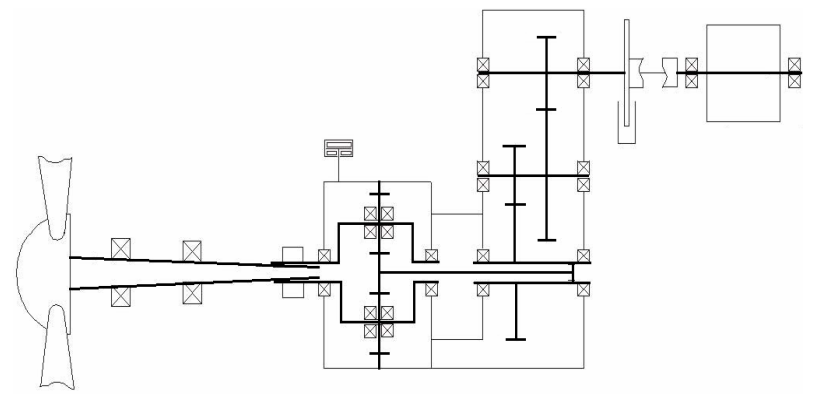

Figure 4. Modular configuration GB-R80.

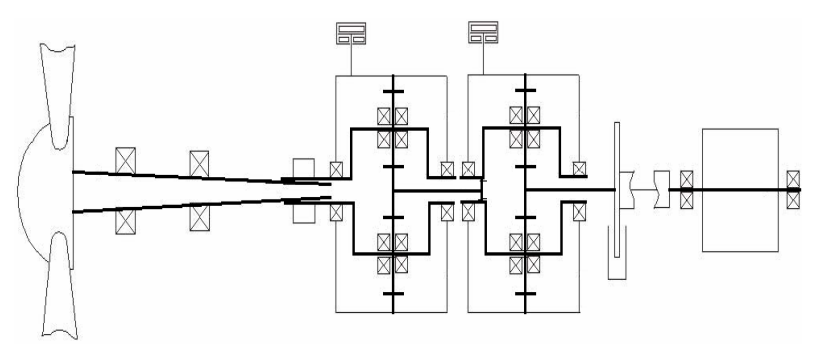

Figure 5. Modular configuration GB-R100-S.

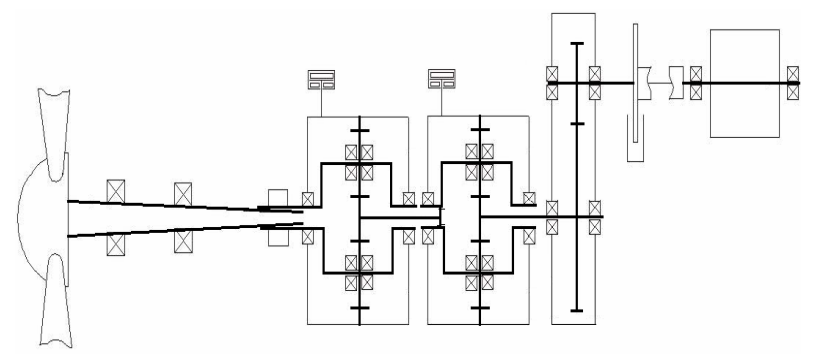

Figure 6. Modular configuration GB-R100-A.

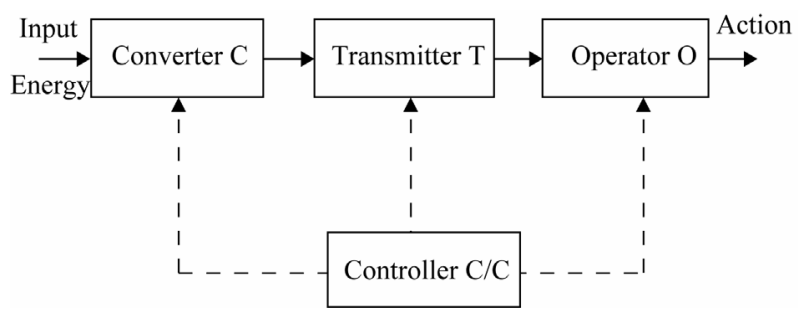

Figure 7. Law of completeness of system parts [9]. stage of the gearbox [transmitter] into components by the technique of functional block diagrams, and complete these functional block diagrams of components concerned by the interaction between shaft and housing, for example lubrication (Figures 8 and $\mathbf{9}$ ).

\section{Behavioral Models}

\subsection{Performances}

The available energy per year per unit area on the site is:

$$
E_{a p}=\frac{8760}{1000} \cdot \frac{\rho}{2} \cdot \int_{v_{i}}^{v_{f}} V^{3} \cdot f(v) \cdot C_{p} \cdot \eta_{g} \cdot A \cdot \mathrm{d} v
$$

\subsection{Cost Modeling}

We present the cost model gearbox based on the definition of specific cost and the estimation of the mass.

$$
\text { Cost }=\text { Cost }_{\text {specific }} \times \text { Mass }
$$

The mass of the gearbox is given as a function of design variables $[10,11]$. Mass models the different configurations studied are given in the following [12].

- Gearbox composed of two or three stages planetary

$$
W_{m p}=8.029 \times F_{s} \times F_{m p e} \times C_{n} \times F_{w p e} \times \sum_{i=1}^{n} \frac{1}{r_{s}^{i}}
$$

$W_{m p}:$ Gearboxes mass $(\mathrm{Kg})$

$C_{n}$ : Rated torque $(\mathrm{N} \cdot \mathrm{m})$

$F_{s}$ : Service factor related to the rotor speed control

$F_{m p e}$ : factor with: $F_{m p e}=\frac{0.4}{F_{m c e}}$

$F_{\text {mce }}$ : Design factor

\begin{tabular}{cccc}
\hline$C_{n}$ & $<200 \mathrm{KN} \cdot \mathrm{m}$ & $200 \leq \cdots<700 \mathrm{KN} \cdot \mathrm{m}$ & $\geq 700 \mathrm{KN} \cdot \mathrm{m}$ \\
$F_{\text {mce }}$ & 850 & 950 & 1100 \\
\hline
\end{tabular}

$F_{\text {wpe }}:$ Weight factor

$F_{w p e}=\frac{1}{n_{w}}+\frac{1}{n_{w} r_{s n}}+r_{s n}+r_{s n}^{2}+\frac{0.4\left(r_{s}-1\right)^{2}}{n_{w}} \times\left(1+\frac{1}{r_{s n}}\right)$

$n$ : Number of stage 2 or 3

$r_{s}$ : Report stage

$r_{s}=r_{0}^{\frac{1}{3}}:$ Gearbox three-stage planetary gear

$r_{s}=r_{0}^{\frac{1}{2}}:$ Gearbox two-stage planetary gear

$r_{s n}$ : Report wheel $r_{s n}=\frac{r_{s}}{2}-1$

$r_{0}$ : report gearbox

$n_{w}$ : Number of satellites per stage

- Three-stage parallel gearbox 


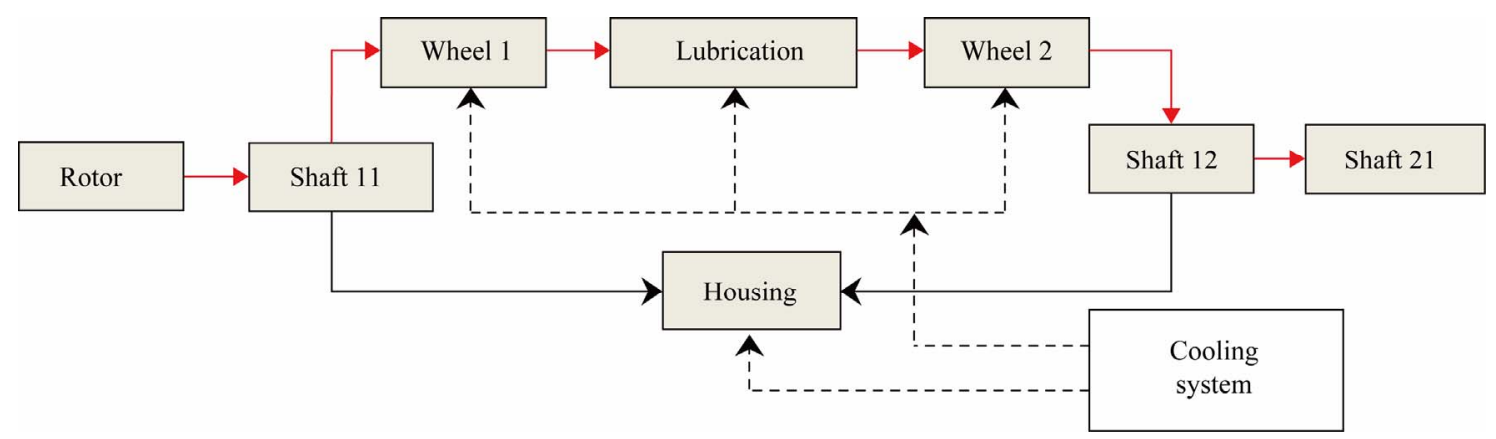

Figure 8. Functional block diagram of a single stage-level 4.

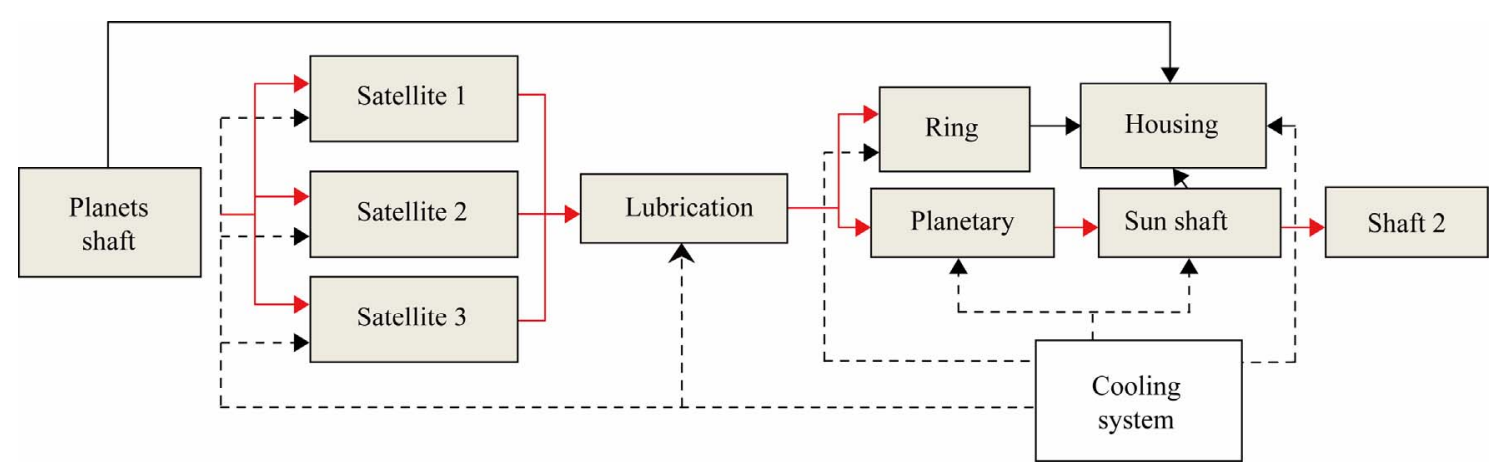

Figure 9. Functional block diagram of a planetary stage-level 4.

$$
W_{m p}=8.029 \times F_{s} \times F_{m p p} \times C_{n} \times F_{w p p} \times \sum_{i=1}^{n} \frac{1}{r_{s}^{i}}
$$

$F_{m p p}$ : factor with: $F_{m p p}=\frac{0.4}{F_{m c p}}$

$F_{m c p}:$ Design factor

\begin{tabular}{cccc}
\hline$C_{n}$ & $<200 \mathrm{KN} \cdot \mathrm{m}$ & $200 \leq \cdots<700 \mathrm{KN} \cdot \mathrm{m}$ & $\geq 700 \mathrm{KN} \cdot \mathrm{m}$ \\
$F_{m c p}$ & 925 & 1000 & 1100 \\
\hline
\end{tabular}

$F_{\text {wpp }}$ : Weight factor

$$
F_{w p p}=1+\frac{1}{r_{s}}+r_{s}+r_{s}^{2}
$$

- Gearbox three-stage consisting of two planetary gears and one parallel

We use the first two stages value $r_{s}$ different.

$$
r_{s}=\left(\frac{r_{0}}{2.5}\right)^{\frac{1}{2}}
$$

$i=1,2$ for the relation (3) from a stage to planetary gear train. rs taking the value 2.5 , and $i=3$ in the relationship (5) of a stage parallel.

\subsection{Reliability Analysis}

Reliability is the characteristic of a system expressed by the probability that performs the function for which it was designed, under given conditions and for a given period (NF X060-010-AFNOR (1991)). Thus, the life of a system is used to measure the amount of service provided. In general, we measure the lifetime of a system by the number of hours they actually worked.

According to the theory reliability, the failure rate can be defined as: [13]

$$
\lambda=\frac{1}{\mathrm{MTTF}}
$$

MTTF: Mean Time to Failure.

The failure rate function of almost all systems obeys from the bath-tube curve Figure 10, suggested that it is reasonable to consider that most WT subassemblies lie in the bottom of this curve, i.e. that they have a fixed failure rate, this hypothesis defines the transition rate as the inverse of the average duration of operation [14].

Reliability is defined from the failure rate $\lambda$, which varies with time. It is shown that the reliability of a system whose failure rate is constant over time is:

$$
R(t)=e^{-\lambda t}
$$

In complex systems, the use of techniques such as functional block diagrams decomposes the problem into components or subsystems. These methods can be used for the allocation of reliability, by translating the objective reliability of the overall system into specific objectives for components that are easier to control. 


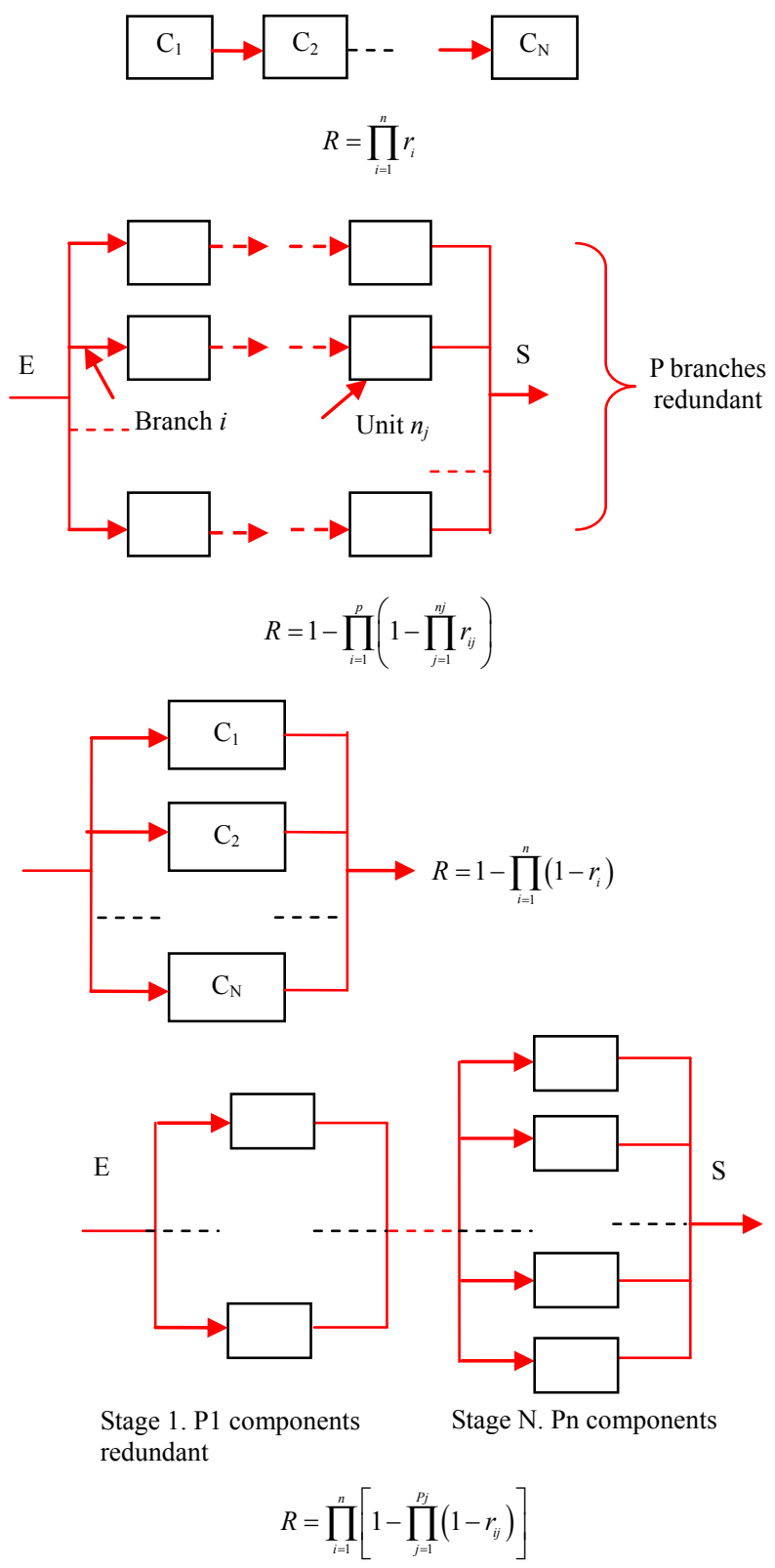

To understand the interest of such a configuration view of reliability, a study is made of the failure rate estimated for two stages different parallel and planetary gear, based on functional block diagrams and regardless of the housing, lubricating and accessories [15].

From these results in (Figures 11 and 12) the planetary stage appears more reliable than a parallel stage, although it contains more components, it can be justified by the load distribution on three satellites instead of a single wheel.

In order to evaluate the reliability of a gearbox of a wind turbine and its impacts on overall performance, we give in (Table 2 ) the estimated failure rate of the different components for three configurations to calculate the total reliability of each gearbox based on the (Figures 8

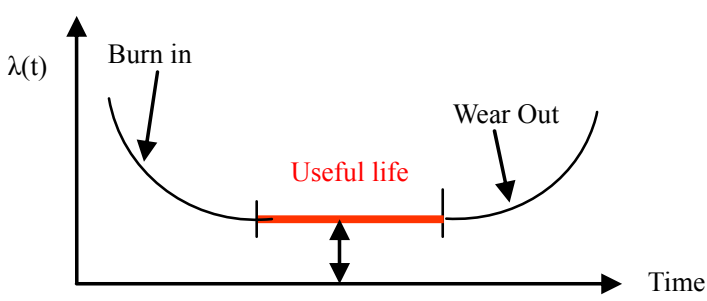

Figure 10. The bath-tub curve.

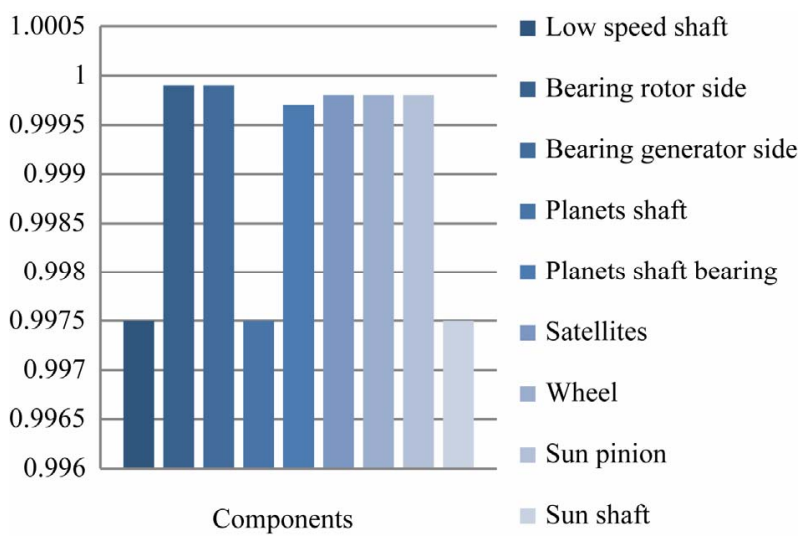

Figure 11. Predicted reliability components of a planetary stage (year).

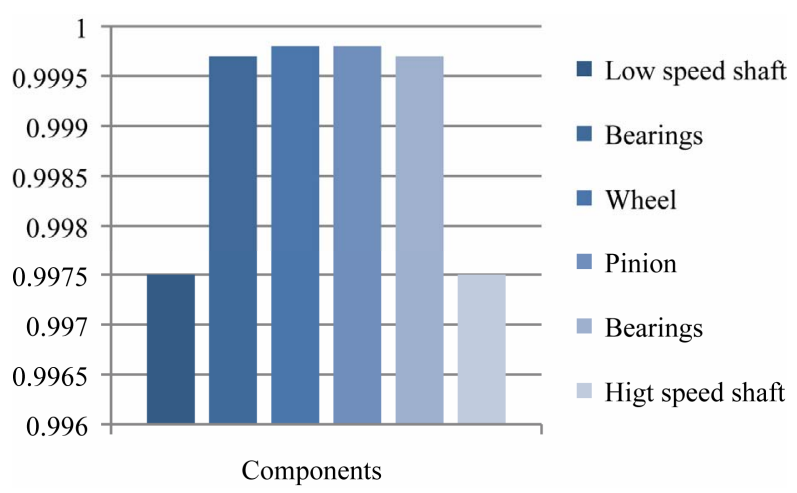

Figure 12. Predicted reliability of the components of a stage parallel (year).

and 9) [15].

\subsection{Qualification}

The qualification criteria of a system are: the performance (criteria), reliability and cost. These three criteria form the main components of the quality indicator of a system defined by ISO [16]:

$$
\mathrm{IQ}=\frac{C_{r} \times \text { Reliability }}{C_{\text {Total }}}
$$

The main performance is related to the service function (FS), performance secondary is related to constraints functions (FC). The identification of performance is achieved during the phase functional analysis, it requires 
an analysis of external environments, they are expressed by the assessment criteria, their level expresses the limit values. The estimation of the performance and cost requires the development of models of system components and external environments. The reliability of a system can be calculated by determining that of each component that constitutes it.

\section{Syntheses of Results}

As shown in (Figure 13), the relative ranking of the three configurations of the gearbox considered in relation to the quality indicator suggests that the configuration GB$\mathrm{R} 100-\mathrm{S}$ is the most qualified. This could be expected since this configuration has fewer components.

\section{Conclusions}

In this paper we present a generic approach to introduce the analysis of reliability as a criterion for decision aid in choice of a solution, the choice criterion used is the quality indicator based on the estimated reliability, weight and performance related to the service function of the product. Modular structures and their definitions have been developed, including all critical components affecting the reliability of a gearbox. The estimated failure rate of critical components in a gearbox NSWC07 [17] is used in this work. Improved estimates of the reliability of a gear-box is possibly using the data of failure more realistic operation, if they became available in the future. An exchange between the different stakeholders, manufacturers

Table 2. Failure rates and reliability estimates of the three configurations.

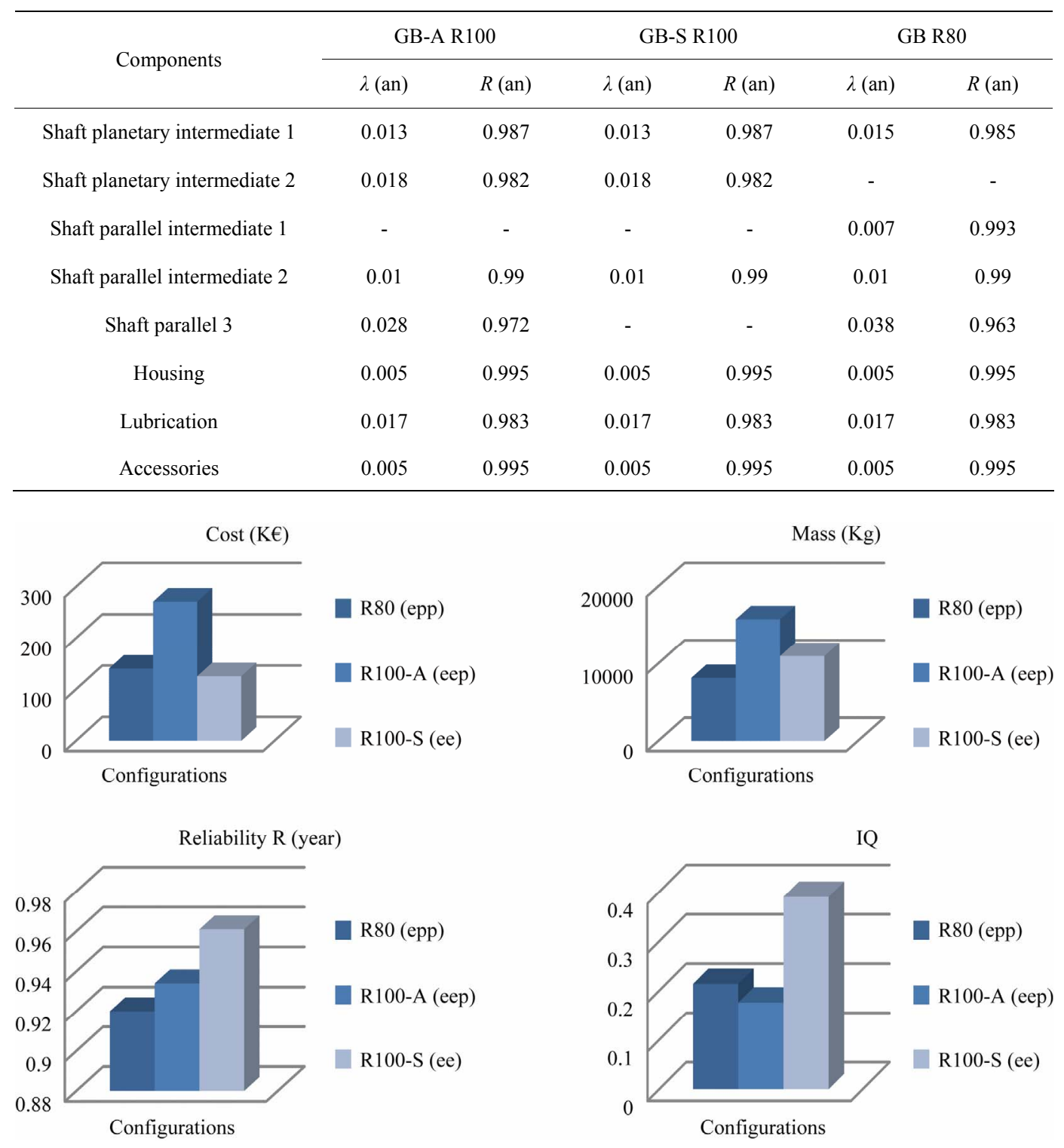

Figure 13. Different results for the three configurations. 
of wind turbine, gearboxes and bearings are essential to reduce the uncertainty of reliability estimates to determine and/or validate the reliability models, and improve overall reliability and thus increase the availability of wind turbine.

Designing a system from the knowledge already structured in a knowledge base which relies on a reliability analysis can provide the different elements necessary for decision making by the designer, and therefore a tool to assist the design. The reliability analysis from the phase of preliminary design allows control of effects induced by their inclusion in the models. Physical modeling of these effects induced at the level of elementary components and interactions will control the behavior of the product and its reliability for greater accuracy indecision making.

\section{REFERENCES}

[1] D. G. Ullman, "The Mechanical Design Process," 3rd Edition, McGraw-Hill Higher Education, New York, 2003.

[2] L. Zimmer and P. Zablit, "Global Aircraft Predesigned Based on Constraint Propagation and Interval Analysis," Proceedings of CEAS Conference on Multidisciplinary Aircraft Design and Optimization, Köln, 25 June 2001.

[3] X. Fischer, P. Sébastian, J. P. Nadeau and P. Joyot, "Conception Inversée Intégrée: Pré-Dimensionnement de Produits Par Satisfaction de Contraintes," Mécanique et Industrie, Vol. 3, No. 4, 2002, pp. 593-606. doi:10.1016/S1296-2139(02)01204-6

[4] M. Sallaou, J. Pailhès and J. P. Nadeau, "Taxonomie des Connaissances en Conception Préliminaire," CFM 2009, Marseille, 2009.

[5] F. Spinato, P. J. Tavner, G. J. W. Van Bussel and E. Koutoulakos, "Reliability of Wind Turbine Subassemblies," IET Renewable Power Generation, Vol. 3, No. 4, 2009, pp. 1-15. doi:10.1049/iet-rpg.2008.0060
[6] M. Sallaou, "Taxonomie des Connaissances et Exploitation en Conception Préliminaire," Application à un Système Eolien, Thèse, ENSAM CER, Bordeaux, 2008.

[7] K. Smolders. "Reliability Analysis of Gearbox," RELIAWIND Project Report-Task 2.4, 2009.

[8] S. D. Savransky, "Engineering of Creativity: Introduction to TRIZ Methodology of Inventive Problem Solving," CRC Press, London, 2000. doi:10.1201/9781420038958

[9] P. Jérôme, M. Sallaou, J. P. Nadeau and G. M. Fadel., "Energy Based Functional Decomposition in Preliminary Design," Journal of Mechanical Design, Vol. 133, No. 5, 2011, 12 p.

[10] R. Harrison and G. Jenkins, "Parametric Cost Modeling of Wing Energy Conversion Systems," 9th BWEA Conference, Edinburgh, 1987, pp. 259-264.

[11] R. Harrison, G. Jenkins and R. J. Taylor, "Cost Modeling of Horizontal Axis Wind Turbines-Results and Conclusions," Wind Engineering, Vol. 13, No. 6, 1989, pp. 315-323.

[12] R. Harrison and G. Jenkins, "Cost Modeling of Horizontal Axis Wind Turbines," ETSU W/34/00170/REP, University of Sunderland, Sunderland, 1994.

[13] R. Billinton and H. Chen, "Assessment of Risk-Based Capacity Benefit Factors Associated with Wind Energy Conversion Systems," IEEE Transactions on Power Systems, Vol. 13, No. 3, 1998, pp. 1191-1196. doi: $10.1109 / 59.709119$

[14] P. J. Tavner, J. Xiang and F. Spinato, "Reliability Analysis for Wind Turbines," Wind Energy, Vol. 10, No. 1, 2007, pp. 1-18. doi:10.1002/we.204

[15] K. Smolders, H. Long, Y. Feng and P. J. Tavner, "Reliability Analysis and Prediction of Wind Turbine Gearboxes," European Wind Energy Conference, Warsaw, 20-23 April 2010.

[16] G. Spinnler, "Conception des Machines: Principes et Applications," Presses Polytechniques et Universitaire Romandes, Lausanne, 2001.

[17] NSWC07, "Handbook of Reliability Prediction Procedures for Mechanical Equipment," 2007. 